\title{
EROSÃO MARGINAL: MUDANÇAS GEOMORFOLÓGICAS NO RIO TELES PIRES (MT) DECORRENTE DA IMPLANTAÇÃO DE UM BARRAMENTO
}

\begin{abstract}
Leila Nalis Paiva da Silva Andrade
Doutora em Ciências pela Universidade Federal de São Carlos. Professora Assistente do Curso de Geografia da Universidade do Estado de Mato Grosso, Campus de Cáceres. Pesquisadora do Laboratório de Pesquisa e Estudos em Geomorfologia Fluvial "Sandra Baptista da Cunha" - UNEMAT

leilaandrade@unemat.br
\end{abstract}

Marcela Bianchessi da Cunha Santino Professora Associada do DHb da Universidade Federal de São Carlos. Professora e Orientadora do Programa de Pós-Graduação em Ecologia e Recursos Naturais/UFSCar, Campus de São Carlos cunha santino@ufscar.br

Celia Alves de Souza Professora no curso de Geografia e nos Programas de Pós-Graduação em Geografia e Ciências Ambientais na Universidade do Estado de Mato Grosso - UNEMAT celiaalvesgeo@globo.com

Fabio Leandro da Silva Doutorando do Programa de Pós-Graduação em Ecologia e Recursos Naturais pela Universidade Federal de

São Carlos - UFSCar fabioleodasilva@gmail.com

Juberto Babilônia de Sousa jubertobabilonia@yahoo.com.br

Cristiano Campos de Miranda

Professor Assistente na Faculdade de Ciências Exatas e Tecnológicas na Universidade do Estado de Mato Grosso - UNEMAT cristiano@fisica.ufmt.br

\section{RESUMO}

A pesquisa teve como objetivo quantificar a erosão marginal e identificar os efeitos hidrológicos e geomorfológicos com a instalação e funcionamento da Usina Hidrelétrica UHE Colider. Foram realizados: levantamento bibliográfico; trabalho de campo no período de dois anos para coleta de solo, instrumentalização e monitoramento da erosão marginal; trabalho de gabinete com confecção de croquis, cálculo da magnitude da erosão e análise em laboratório. Averiguou-se que as margens erodiram lentamente, passando a incidir o processo de abrasão. No entanto, pode-se constatar que a erosão aumentou $12 \%$ em 2018 se comparada a 2017. Ao correlacionar os fatores (velocidade, vazão, inclinação, altura do barranco e outros) verificou-se que Análise do Componente Principal explicou $63 \%$ da variação observada. No reservatório as margens e várias ilhas foram submersas, prejudicando o habitat de várias espécies. Conforme as transformações ocorridas com a instalação da UHE Colider, se não forem tomadas medidas de contensão das erosões marginais, provavelmente ocorrerá aumento dos processos erosivos.

Palavras-chave: Processos erosivos. UHE Colider. Mudança na Paisagem. Bacia Amazônica.

\section{BANK EROSION: GEOMORPHOLOGICAL CHANGES IN THE TELES PIRES RIVER (MT) DUE TO THE INSTALLATION OF A DAM}

\begin{abstract}
The objective of this research was to quantify the river bank erosion and identify the hydrological and geomorphological effects following the installation and operation of the Colider Hydroelectric Power Plant (HPP). We conducted a bibliographical survey; fieldwork, over a two-year period, for soil collection, instrumentation and monitoring of bank erosion; and deskwork to create sketches, calculate the magnitude of erosion, and conduct
\end{abstract}

Caminhos de Geografia $\quad$ Uberlândia-MG $\quad$ v. 21, n. $75 \quad$ Jun/2020 $\quad$ p. 154-171 Página 154




\begin{abstract}
laboratory analyses. We verified that the river banks eroded slowly, beginning to precipitate the corrosion process. However, erosion was $12 \%$ greater in 2018 than to 2017 . When correlating thel factors (velocity, flow, slope, ravine height and others) the Principal Component Analysis explained $63 \%$ of the variation observed. In the reservoir, the banks and several islands were submerged, damaging the habitat of various species. The transformations due to the installation of the Colider HPP imply an increase in the erosive process.
\end{abstract}

Keywords: Erosive Processes. Colider HPP. Landscape change. Amazon Basin.

\title{
INTRODUÇÃO
}

A dinâmica dos rios promove mudanças físicas que contribuem com a esculturação da rede de drenagem, entalhando os canais de escoamento. A ação ativa dos rios condiciona o surgimento de ilhas, baías, lagoas e bancos de sedimentos que resultam na morfologia hídrica. A hidrossedimentologia ao longo dos tempos moldam as condições hidrogeomorfológicas das bacias hidrográficas (CHRISTOFOLETTI, 1981; SUGUIO, 2003; CUNHA, 2013; STEVAUX e LATRUBESSE, 2017). Esse resultado advém das interações conjuntas dos fatores geoambientais, permitindo o funcionamento do sistema fluvial como: erosão, transporte e deposição do material intemperizado. Os ambientes lóticos são grandes agentes entalhadores e transformadores do relevo, sendo esse processo decorrente da erosão vertical e marginal (LABADESSA, 2014). Os rios são os principais agentes de erosão; sua dinâmica natural, resulta no processo de arrasamento das proeminências desde a parte mais alta (alto curso), consideradas áreas de degradação, até a zona mais baixa (foz) com a agradação dos sedimentos (CHRISTOFOLETTI, 1981; CUNHA e GUERRA, 1996; SUGUIO, 2003).

A erosão fluvial é o resultado de novas formas do relevo exercida pelos trabalhos dos rios, vertentes e interflúvios com a remoção do material da margem e fundo pelas forças atuantes: solo, vegetação e fatores climáticos (CHRISTOFOLETTI, 1981; GATTO, 1988; WOOD e ARMITAGE, 1997; SUGUIO, 2003; RINALDI e DARBY, 2007; LABADESSA, 2014). Assim, a erosão fluvial está associada a vários fatores ambientais que contribuem com a modelagem fluvial e esculturação da paisagem (PENTEADO, 1974; SILVA et al., 2007; RICCOMINI et al., 2009; ALLAN e CASTILLO, 2007).

Autores como Rosgen (2001), Souza (2004), Bettes (2008), Balasubramanian (2010), Cunha (2013), Pomerol et al. (2013), Souza e Almeida (2015) afirmam que a capacidade erosiva das margens e do leito, bem como todo o processo da dinâmica fluvial está condicionada aos fatores hidroclimáticos e o material de origem, e qualquer mudança que ocorre no sistema fluvial ocasionam consequências graves no auto ajuste da bacia hidrográfica. $E$ ações antropogênicas podem alterar o regime hídrico, i.e. erosão, aumento da carga sedimentar o que contribui com o assoreamento dos rios (GATTO, 1988; CASADO et al., 2002; BORTOLUZZI e PETRY, 2008; MINELLA e MERTEN, 2013; CARVALHO e HORA, 2018; MIRANDA et al., 2018).

A erosão fluvial consiste na remoção de partículas do leito e das margens por parte do escoamento, sendo resultado da interação do rio e de seus limites físicos. Constitui um fenômeno natural que, sendo de evolução lenta, pode durar meses ou até anos, assumindo consequências devastadoras para a estabilidade do sistema fluvial (FERNANDEZ e FULFARO, 1993; PINTO, 2017). A erosão ocorre nos diferentes tipos de solos granulares e compostos, estando esse processo relacionado a ruptura do equilíbrio entre as forças resistentes e atuantes (vegetação, solo, rocha e declividade); neste sentido, qualquer mudança a montante ou jusante ocasiona o desequilíbrio na rede hidrográfica. Assim, a erosão das margens é o resultado desse processo erosivo condicionada pela ação natural ou acelerada pelas atividades antrópicas (CASADO et al., 2002; LABADESSA, 2014).

A erosão acelerada das margens dos rios é uma das principais causas da poluição de fontes não pontuais associada a fornecimento e aumento dos sedimentos (ROSGEN, 2001). A interferência humana acarreta mudanças na estrutura e no funcionamento dos sistemas lóticos, comprometendo tanto os processos ecológicos quanto socioeconômicos associados aos ambientes fluviais (PAPANICOLAOU et al., 2006). Os problemas podem relacionar-se a turbidez da água, alteração na

$\begin{array}{llll}\text { Caminhos de Geografia } \quad \text { Uberlândia-MG } & \text { v. 21, n. } 75 \quad \text { Jun/2020 } & \text { p. 154-171 Página } 155\end{array}$


dinâmica dos sedimentos, perda de terras agricultáveis (LAWLER et al., 1997; KARMAKER e DUTTA, 2010). As partículas que são desagregadas das margens são um indicador para o entendimento dos processos hidrossedimentológicos (HOOKE, 1979; MEYBECK et al., 1996; RINALDI e DARBY, 2007).

Thorne (1978), Gatto (1988), Resende et al. (1992), Almeida (2004), Bandeira (2005), Ramos et al. (2012) afirmam que solos não coesos: a areia fina, cascalhos e o silte favorecem a erosão marginal. Quanto maior o grau de coesão, menor será o cisalhamento nas margens. Enquanto que nos solos mais coesos, como o caso da argila, tendem a dificultar a erosão pelo fato de apresentar mais coesão e plasticidade. No entanto, Bettes (2008) ressalta que em várias situações o barranco coeso e não coeso podem ter reações semelhantes.

Thorne (1978) complementa que a força de estresse é responsável por explicar a energia e resistência do banco em relação a erosão marginal. Essa força é a unidade de área atuando na superfície. Assim, a geometria da margem influencia no processo erosivo, aumentando a energia cisalhante. De acordo com Lawler et al. (1997) nas margens coesas a erosão ocorre lentamente pelas forças mecânicas. Nesta situação, Gatto (1988) ressalta que as forças mecânicas indicam a quantidade de resistência que o sedimento ou depósitos oferecem em relação a forças de tração, compressão e cisalhamento.

As mudanças ocasionadas nas calhas dos rios estão constantemente contribuindo com alterações significativas, que podem ser irreversíveis. As obras de engenharia na construção de reservatórios para diversos fins implicam em efeitos local, regional e global (COELHO, 2008; CUNHA, 2013). A construção de barragens modifica e rompe a funcionalidade natural dos rios. A montante, a tendência é a retirada da vegetação para construção do reservatório, a colmatagem de afluentes, a diminuição da vazão até o ambiente lótico torna-se lêntico, com o processo de deposição e sedimentação das partículas. A jusante, ocorre a mudança na morfologia com o entalhamento do canal devido a redução da largura, o aumento da profundidade e o aceleramento da erosão marginal (COELHO, 2008).

O rio Teles Pires, como unidade de análise dessa pesquisa passou por mudanças significativas na década de 1980, com a ocupação, principalmente a região norte mato-grossense. Muitas áreas foram desmatadas para construções de casas, comércios, atividades agropecuárias e madeireiras. Após a colonização, os espaços foram aos poucos se regenerando. No entanto, o desenvolvimento agrícola em larga escala e a construção de hidroelétricas estão contribuindo com novas mudanças na paisagem. Neste contexto, os fatores antrópicos e naturais condicionam mudanças no meio físico, e tende acelerar com a ação humana.

Os estudos em redes de drenagens são extremamente importantes, uma vez que a crescente demanda da água tem aumentado nos últimos anos. Os tipos de uso direto e indireto tem proporcionado mudanças de ordem ecossistêmica nos ambientes fluviais. Deste modo, a pesquisa teve como objetivos quantificar a erosão marginal e averiguar os efeitos hidrológicos e geomorfológicos decorrente da instalação da Usina Hidrelétrica de Colider, nos municípios de Itaúba, Colider e Nova Canaã do Norte. A hipótese que permeou esse estudo considerou que a construção e instalação de um barramento no rio, associado ao desmatamento acelera a erosão marginal no médio curso do rio Teles Pires, estado do Mato Grosso.

\section{MATERIAL E MÉTODOS}

\section{Descrição da área de estudo}

A área de estudo compreende o médio curso do rio Teles Pires, trecho que percorre entre os municípios de Colider, Itaúba e Nova Canaã do Norte com $124 \mathrm{~km}$ de extensão. Localiza-se entre as

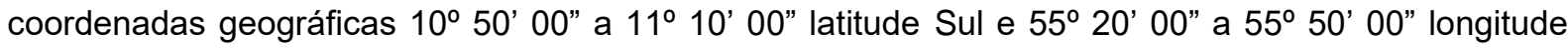
Oeste (Figura 1). 
Leila Nalis Paiva da Silva Andrade

Marcela Bianchessi da Cunha Santino

Celia Alves de Souza

Fabio Leandro da Silva

Erosão marginal: mudanças geomorfológicas no rio Teles Pires (MT) Juberto Babilônia de Sousa decorrente da implantação de um barramento Cristiano Campos de Miranda

Figura 1 - Localização da área de estudo a montante e a jusante da UHE Colider e os pontos de monitoramento (P1 a P8) da erosão fluvial.
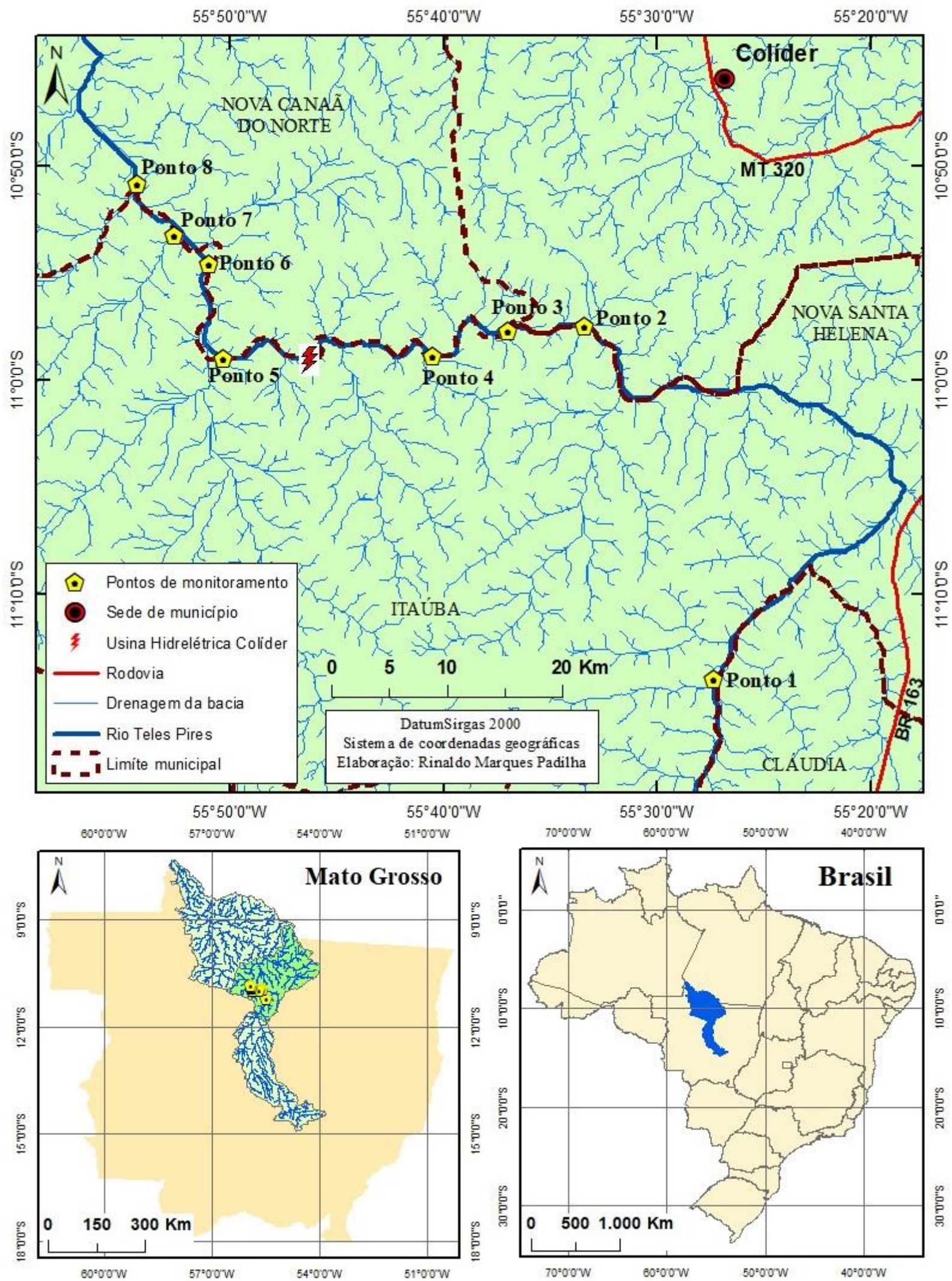


\section{Monitoramento in situ da erosão marginal}

O monitoramento da erosão foi realizado em 8 pontos no rio Teles Pires (4 a montante e 4 a jusante da UHE Colider; Tabela 1), sendo considerados três períodos de estiagem: 2016 (julho), 2017 (julho) e 2018 (julho). Em julho de 2016 foram coletadas amostras de solo das margens dos 4 pontos monitorados a jusante (P5 a P8: Tabela 1) e no primeiro ponto a montante (P1) da UHE Colider. Não foram coletados materiais e sim quantificados a altura do barranco e os dados hidrodinâmicos nos pontos a montante (P2, P3 e P4) devido ao fato de que essa região ter sido inundada pelo reservatório (início da formação do lago em 2017).

Tabela 1 - Pontos monitorados no corredor fluvial do rio Teles Pires nos municípios Colíder, Itaúba e Nova Canaã do Norte. Em que: MD - Margem Direita; ME - Margem Esquerda.

\begin{tabular}{|c|c|c|c|c|c|c|}
\hline \multirow[b]{2}{*}{ Ponto } & \multicolumn{4}{|c|}{ Coordenadas Geográficas } & \multirow{2}{*}{\multicolumn{2}{|c|}{ Municípios }} \\
\hline & \multicolumn{2}{|c|}{ Latitude Sul } & \multicolumn{2}{|c|}{ Longitude Oeste } & & \\
\hline 1 (montante) & \multicolumn{2}{|c|}{$11^{\circ} 14^{\prime} 0.6^{\prime \prime}$} & \multicolumn{2}{|c|}{$55^{\circ} 27^{\prime} 17.81^{\prime \prime}$} & \multicolumn{2}{|l|}{ Itaúba } \\
\hline 2 (montante) & \multicolumn{2}{|c|}{$10^{\circ} 57^{\prime} 28.46^{\prime \prime}$} & \multicolumn{2}{|c|}{$55^{\circ} 33^{\prime} 22.67^{\prime \prime}$} & Itaúba/Colider & \\
\hline 3 (montante) & \multicolumn{2}{|c|}{$\begin{array}{l}10^{\circ} 57^{\prime} 43.6 " \\
10^{\circ} 58^{\prime} 513 "\end{array}$} & \multicolumn{2}{|c|}{$\begin{array}{l}55^{\circ} 36^{\prime} 55.5^{\prime \prime} \\
55^{\circ} 40^{\prime} 27.3^{\prime \prime}\end{array}$} & Itaúba/Colider & \\
\hline 4 (montante) & \multicolumn{2}{|c|}{$10^{\circ} 58 ’ 51.3 "$} & \multicolumn{2}{|c|}{$55^{\circ} 40^{\prime} 27.3^{\prime \prime}$} & $\begin{array}{l}\text { Nova Canaã } \\
\text { Norte/ltaúba }\end{array}$ & \\
\hline \multirow[t]{2}{*}{5 (jusante) } & MD & ME & MD & ME & \multirow{2}{*}{\multicolumn{2}{|c|}{$\begin{array}{l}\text { Nova Canaã } \\
\text { Norte/Itaúba }\end{array}$}} \\
\hline & $10^{\circ} 59^{\prime} 00.3^{\prime \prime}$ & $10^{\circ} 59^{\prime} 09.8^{\prime \prime}$ & $55^{\circ} 50^{\prime} 17.4^{\prime \prime}$ & $55^{\circ} 50^{\prime} 16^{\prime \prime}$ & & \\
\hline 6 (jusante) & $10^{\circ} 54^{\prime} 04.5^{\prime \prime}$ & $10^{\circ} 54^{\prime} 00.2^{\prime \prime}$ & $55^{\circ} 50^{\prime} 17.2 \prime$ & $55^{\circ} 50^{\prime} 23.2^{\prime \prime}$ & $\begin{array}{l}\text { Nova Canaã } \\
\text { Norte/Itaúba }\end{array}$ & do \\
\hline 7 (jusante) & $10^{\circ} 53^{\prime} 05.6^{\prime \prime}$ & $10^{\circ} 53^{\prime} 14.1^{\prime \prime}$ & $55^{\circ} 52^{\prime} 23^{\prime \prime}$ & $55^{\circ} 52^{\prime} 31.7^{\prime \prime}$ & $\begin{array}{l}\text { Nova Canaã } \\
\text { Norte/Itaúba }\end{array}$ & do \\
\hline 8 (jusante) & $10^{\circ} 50^{\prime} 51.2^{\prime \prime}$ & $10^{\circ} 50^{\prime} 51.33^{\prime \prime}$ & $55^{\circ} 54^{\prime} 13.1^{\prime \prime}$ & $55^{\circ} 54^{\prime} 23.4^{\prime \prime}$ & $\begin{array}{l}\text { Nova Canaã } \\
\text { Norte/Itaúba }\end{array}$ & do \\
\hline
\end{tabular}

Em que: $\mathrm{MD}=$ Margem Direita; $\mathrm{ME}=$ Margem Esquerda.

Os pontos foram distribuídos em 3 grupos de acordo com o dendograma vertical. No primeiro grupo os pontos P8ME e P7MD, P1ME e P8MD apresentaram mais semelhanças entre si, por possuírem menor distância. No segundo formaram dois pequenos grupos com os pontos P6MD e P6ME, P5MD e P5ME e o P7ME constituiu o último grupo do dendograma, por não possuir semelhança em relação aos outros. As variáveis que mais permitiram ao agrupamento foram: profundidade, inclinação e vazão (Figura 2).

Figura 2 - Dendograma dos pontos monitorados no médio curso do rio Teles Pires. Em que: MD= Margem Direita; $\mathrm{ME}=$ Margem Esquerda.

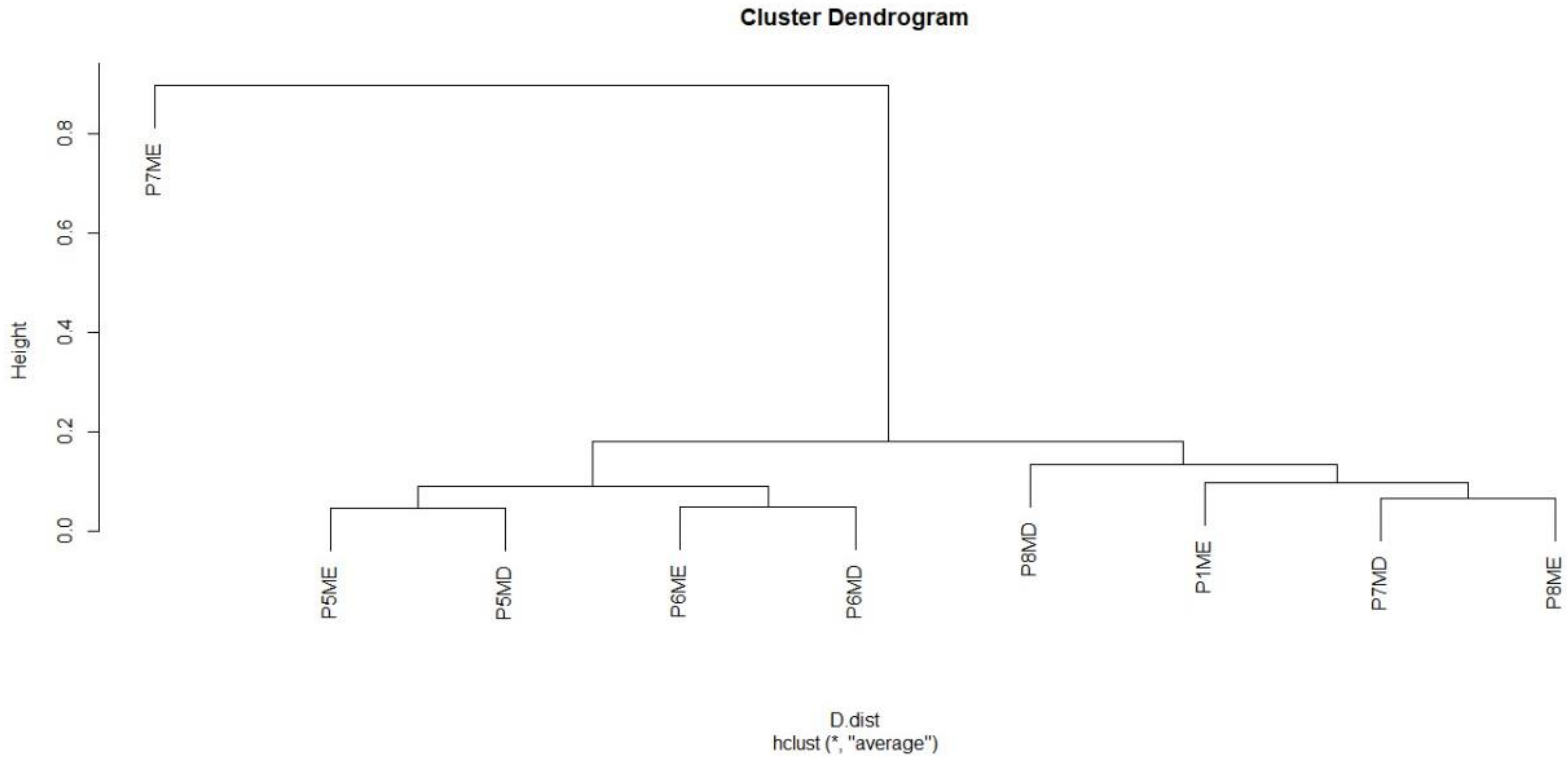


Utilizou-se a técnica de pinos empregadas por Souza e Cunha (2009), Araujo e Rocha (2012), Dias (2012) para quantificar a erosão marginal. Essa técnica consiste na inserção perpendicular de pinos de aço (i.e. vergalhão 3/4) que podem medir de 10 a $80 \mathrm{~cm}$ de comprimento (GATTO, 1988). Foram utilizados 50 pinos de $30 \mathrm{~cm}$ para mensurar o valor da erosão por meio da superfície de exposição dos pinos. Primeiramente foi mensurada a altura do barranco e dividido em cinco pontos para inserção dos pinos (Figura 3).

Figura $3(\mathrm{~A})$ - Representação da técnica de pinos e estacas utilizadas no monitoramento da erosão marginal.

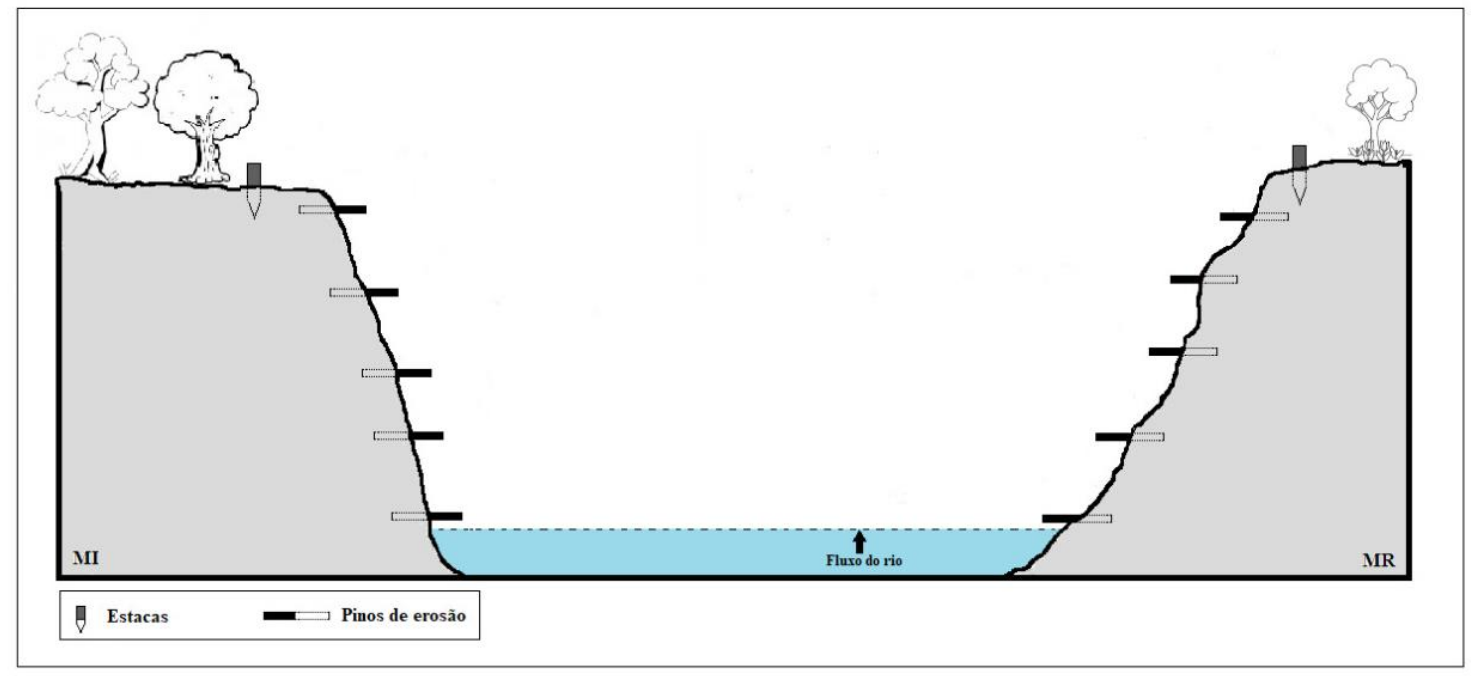

Em que: $\mathrm{Ml}=$ Margem Íngreme; MR= Margem Rampeada .

Figura 3 (B) - Margem fluvial do rio Teles Pires instrumentalizada com pinos e estacas.

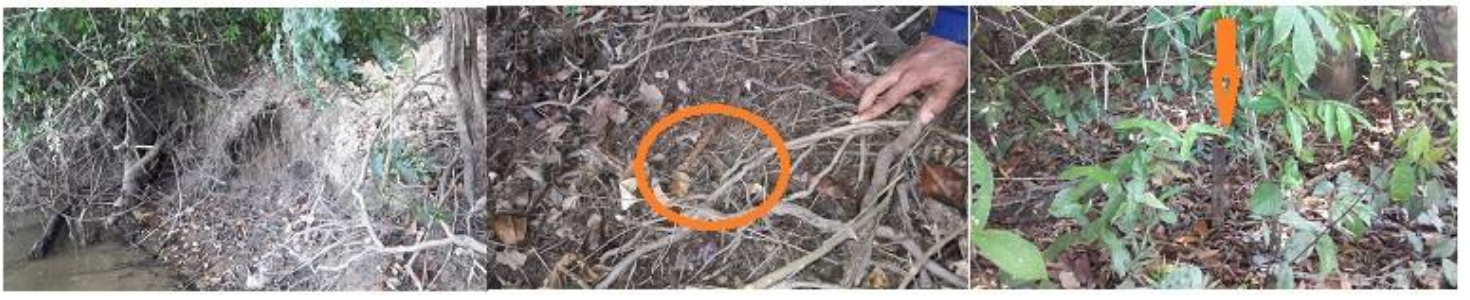

Os pinos foram posicionados no ano de 2016 na posição horizontal com $10 \mathrm{~cm}$ exposto acima do nível da água para quantificação da erosão marginal (Figuras 3A e 3B). A verificação do recuo da margem foi realizada após o período chuvoso (julho de 2017 e 2018), com auxílio de trena com escala de $0,1 \mathrm{~cm}$ para medir a erosão de cada margem do trecho em estudo. Os principais critérios utilizados para definir as seções que foram monitoradas: tipos de margens, afluentes $500 \mathrm{~m}$ a montante ou jusante e proximidades de sede de fazendas, o que facilitou a posterior localização.

Foram instaladas uma 1 estaca em cada margem totalizando 9 estacas nos pontos monitorados. A técnica das estacas é utilizada principalmente para garantir o controle de erosão caso ocorra a perda dos pinos pela erosão por desmoronamentos, como basculamento ou cisalhamento (HUGUES, 1977; HOOKE, 1979; BANDEIRA, 2005; CORREA e SOUZA FILHO, 2009; SILVA, 2009). Essa técnica constitui na instalação de estacas de madeira na posição vertical a $2 \mathrm{~m}$ da margem (Figuras $3 \mathrm{~A}$ e 3B).

A altura das margens foi mensurada em campo com trena escala de $0,1 \mathrm{~cm}$. Para definir os padrões relacionados a altura foi utilizada a proposta de Fernandez e Fulfaro (1993) e Souza (2004) com adaptações para o rio Teles Pires, considerando o intervalo de $2 \mathrm{~m}$ entre o padrão baixo $(0$ a $2 \mathrm{~m})$, médio (de 2 a $4 \mathrm{~m}$ ) e alto (acima de $4 \mathrm{~m}$ ).

Foram coletadas do barranco amostras de solos de $1 \mathrm{~kg}$, sendo armazenadas em sacolas plásticas para análise da composição granulométrica e classe textural, para identificar o fator de erodibilidade. Para sedimentos finos utilizou-se o método da pipetagem e para as partículas grossas empregou o método de peneiramento (POIZOT et al., 2008; EMBRAPA, 1997). 


\section{Quantificação da erosão marginal}

Para quantificar a magnitude da erosão foi utilizada a seguinte Equação 1 sugerida por Hooke (1979), adaptada por Fernandez (1990; 1995):

$$
E m=\left(L_{1}-L_{0}\right) / t \quad(\text { Equação } 1)
$$

Em que: $E m$ = Magnitude da erosão $(\mathrm{cm} / \mathrm{dia}$ ou $\mathrm{cm} / \mathrm{mês}) ; \mathrm{L}_{\mathrm{I}}=$ Comprimento do pino exposto pela erosão; $L_{0}=$ Comprimento exposto inicialmente, padronizada em $10 \mathrm{~cm} ; \mathrm{t}=$ Tempo transcorrido (dias ou meses) entre cada campanha (coleta).

A erosão média para cada seção monitorada é a somatória dos recuos registrados dividido pelo número total de pinos instalados, enquanto a erosão média anual foi a média aritmética da erosão média obtida ao longo de dois anos de monitoramento (HOOKE, 1979). Para a magnitude da erosão acumulada adaptada para esse trabalho, multiplicou o último ano de monitoramento em 24 meses.

Para quantificar o solo erodido foi utilizada a Equação 2 a partir das discussões de Hooke (1979) modificada para essa pesquisa:

$$
V=\operatorname{Vp} \times P e \times 1 \quad \text { (Equação 2) }
$$

Em que: $V=$ Volume $\left(m^{3}\right) ; \mathrm{Dp}=$ Distância entre os pinos $(\mathrm{m}) ; \mathrm{Pe}=$ Pinos erodidos $(\mathrm{m}) ; 1=$ Largura $(\mathrm{m})$.

\section{Análise Estatística}

As variáveis inclinação, área, velocidade, profundidade, vazão, foram testadas nos testes Kruskall Wallis. Ainda nesse sentido, tendo o intuito de analisar possíveis padrões entre as variáveis respostas, uma Análise dos Componentes Principais (ACP) foi realizada. Todo o tratamento estatístico dos dados utilizados no presente estudos foram realizados através do software livre $R$ Core Time.

\section{RESULTADOS E DISCUSSÃO}

O monitoramento das margens é de extrema importância para prevenção dos desmoronamentos que colabora com a perda de áreas adjacentes aos corpos hídricos (FERNANDEZ e FULFARO, 1993; CORREA e SOUZA FILHO, 2009; SILVA et al., 2011; KHEIRALLA e SIDDEG, 2015). E para compreender os processos relacionados a dinâmica das margens direita e esquerda do rio Teles Pires em seu médio curso, os fatores ambientais que, condicionam as mudanças em seu sistema fluvial foram identificados para o entendimento dos processos hidrogeomorfológicos. A paisagem nos últimos anos vem se transformando nessa unidade de análise. Com a ocupação do norte matogrossense muitas áreas de preservação foram retiradas para construção de cidades, práticas agropastoris e recentemente construção de usinas hidrelétricas.

As margens foram classificadas em rampeada e íngreme, com altura entre 3,2 (P6) a 10,70 m (P5), padrão considerado médio e alto, com inclinações de 30 a $90^{\circ}$. O solo das margens apresentou composição interestratificada com maior porcentagem de solos não coesos: areia fina $(2,18 \%$ em P5 a $69,07 \%$ em P6) e o silte $(29,16 \%$ em P6 a $92,47 \%$ em P5) com pouca plasticidade, suscetíveis a erosão. A classe textural corresponde a silte, Franco siltosa e Franco arenosa. Destaca-se, ainda, a vazão média, variou de 724,43 m³/s em P6 a 1.213,55 m³/s em P1 (Tabela 2). 
Tabela 2 - Altura e inclinações dos barrancos, tipo de margem, composição granulométrica, classe textural e vazão das margens a montante e jusante da UHE Colider nos municípios Itaúba, Colider e Nova Canaã do Norte.

\begin{tabular}{|c|c|c|c|c|c|c|c|c|c|c|}
\hline \multirow{3}{*}{ Pontos } & \multirow{2}{*}{\multicolumn{2}{|c|}{ Barranco }} & \multirow{3}{*}{$\begin{array}{l}\text { Tipo de } \\
\text { Margem }\end{array}$} & \multicolumn{5}{|c|}{ Composição das margens\% } & \multirow{3}{*}{$\begin{array}{l}\text { Classe } \\
\text { Textural }\end{array}$} & \multirow[b]{3}{*}{$\begin{array}{l}\text { Vazão } \\
\left(m^{3} / s\right)\end{array}$} \\
\hline & & & & \multicolumn{3}{|c|}{ Areias } & \multirow[b]{2}{*}{ Silte } & \multirow[b]{2}{*}{ Argila } & & \\
\hline & $\begin{array}{c}\text { Altura } \\
(\mathrm{m})\end{array}$ & $\begin{array}{c}\text { Inclinação } \\
\text { () }\end{array}$ & & $\mathbf{G}$ & $\mathbf{M}$ & $\mathbf{F}$ & & & & \\
\hline P1 ME (I) & \multirow[b]{2}{*}{5,20} & \multirow[b]{2}{*}{45} & \multirow[b]{2}{*}{ Rampeada } & 0 & 0 & 10,73 & 81,92 & 4,85 & Silte & \multirow[b]{2}{*}{$1.213,55$} \\
\hline P1 ME (S) & & & & 0 & 0,31 & 40,62 & 53,79 & 5,28 & Franco siltosa & \\
\hline P5 MD (I) & \multirow[b]{2}{*}{10,70} & \multirow[b]{2}{*}{30} & \multirow[b]{2}{*}{ Rampeada } & 0 & 0 & 55,26 & 41,25 & 3,49 & Franco arenosa & \multirow[b]{3}{*}{871,68} \\
\hline P5 MD (S) & & & & 0 & 0 & 64,53 & 33,32 & 2,15 & Franco arenosa & \\
\hline P5 ME (I) & \multirow[b]{2}{*}{4,10} & \multirow[b]{2}{*}{90} & \multirow[b]{2}{*}{ Íngreme } & 0 & 0 & 55,29 & 42,2 & 2,51 & Franco arenosa & \\
\hline P5 ME (S) & & & & 0 & 0 & 2,18 & 92,47 & 5,35 & Silte & \multirow{5}{*}{724,43} \\
\hline P6 ME (I) & \multirow[b]{2}{*}{4,3} & \multirow[b]{2}{*}{90} & \multirow[b]{2}{*}{ Íngreme } & 0 & 0 & 65,54 & 32,95 & 1,51 & Franco arenosa & \\
\hline P6 ME (S) & & & & 0 & 0,1 & 3,26 & 91,61 & 5,03 & Silte & \\
\hline P6 MD (I) & \multirow[b]{2}{*}{3,20} & \multirow[b]{2}{*}{45} & \multirow[b]{2}{*}{ Rampeada } & 0 & 0 & 69,07 & 29,16 & 1,77 & Franco arenosa & \\
\hline P6 MD (S) & & & & 0 & 0 & 31,62 & 65,41 & 2,97 & Franco siltosa & \\
\hline P7 ME (I) & \multirow[b]{2}{*}{3,4} & \multirow[b]{2}{*}{90} & \multirow[b]{2}{*}{ Íngreme } & 0 & 0 & 57,69 & 40,72 & 1,59 & Franco arenosa & \multirow{4}{*}{806,20} \\
\hline P7 ME (S) & & & & 0 & 0 & 67,38 & 30,77 & 1,85 & Franco arenosa & \\
\hline P7 MD (I) & \multirow[b]{2}{*}{3,6} & \multirow[b]{2}{*}{90} & \multirow[b]{2}{*}{ Íngreme } & 0 & 0 & 34,69 & 61,81 & 3,50 & Franco siltosa & \\
\hline P7 MD (S) & & & & 0 & 0 & 35,47 & 61,08 & 3,45 & Franco siltosa & \\
\hline P8 MD (I) & 8,48 & 90 & İngreme & 0 & 0 & 11,90 & 83,08 & 5,02 & Silte & \\
\hline P8 ME (I) & 4,20 & 90 & Íngreme & 0 & 0 & 51,01 & 46,43 & 2,56 & Franco arenosa & 862,91 \\
\hline
\end{tabular}

Em que: MD - Margem Direita; ME - Margem Esquerda; I - Inferior (Próximo a lâmina d'água); S - Superior; G Grossa; M- Média; F - Fina.

No P5 a jusante da UHE Colider na margem direita a altura foi $10,70 \mathrm{~m}$, maior altitude registrada, no entanto, é o barranco mais descaracterizado devido as interferências antrópicas (i.e. área de pesca). O grau de elevação corresponde a $30^{\circ} \mathrm{com}$ índices consideráveis de areia fina na parte (superior e inferior) da margem, classificada como Franco arenosa. Deste modo, o ponto caracteriza-se pelos solos granulares e composto (areia e silte), confirmando as discussões de Pinto (2017), em que os solos granulares os ângulos são inferiores a $90^{\circ}$ graus, a principal característica é a presença de raízes no talude que comporta o material de origem. Nos solos argilosos, a grande maioria possuí margens verticais ou com ângulos superiores a 90ำ devido à sua coesão.

A altura, o grau de inclinação, tipo de margem (rampeada e íngreme) e composição textural são condicionantes importantes para avaliar o processo erosivo nas margens do rio Teles Pires. De acordo com Gatto (1988) à medida que a inclinação do barranco aumenta, a margem fica mais instáveis e suscetíveis a erosão. Essa afirmação depende também do tipo de uso que está sendo desenvolvido nas adjacências, pois em áreas preservadas a tendência é que a erosão ocorra lentamente.

A altura da margem é independente da sua composição, no entanto, nas altitudes mais elevadas os taludes são instáveis, predominam silte e argila, no caso das margens em estudo, sobressaem o silte (FERNANDEZ, 1990). Rubio (2014) afirma que nos estudos realizados na UHE Chavantes, o silte contribuiu com o processo erosivo das margens.

Dias (2012) ainda complementa que a composição textural é decisiva na resistência e erodibilidade das margens. A textura do solo relaciona-se diretamente com atributos importantes para qualidade dos sedimentos (MELLO, 2013). Barrancos ativos criam e mantêm estrutura natural para as funções necessárias ao habitat. As margens conservam um ambiente altamente dinâmico. Assim, erosão marginal modifica as estruturas da vegetação durante as inundações, o que contribui com mudanças no habitat e as funções do ecossistema (FLORSHEIM et al., 2008).

Analisando a composição das margens verificou-se maior porcentagem de silte e areia fina, composição interestratificadas (Tabela 2). Essas partículas são provenientes das rochas de formação: magmática granito e sedimentar arenito, constituindo Neossolos Quartzarênicos e os Neossolos Litólicos (BRASIL, 1980).

A quantidade das duas composições areia e silte apontam um alto índice de susceptibilidade natural a erosão. Contudo, esses resultados devem ser avaliados concomitantemente com outras variáveis

$\begin{array}{lllll}\text { Caminhos de Geografia } \quad \text { Uberlândia-MG } & \text { v. 21, n. } 75 \quad \text { Jun/2020 } & \text { p. 154-171 Página } 161\end{array}$


ambientais. Nesse contexto, Rubio (2014) ressalta que as pesquisas realizadas na UHE Rosana no rio Paranapanema apresentaram solos arenosos, no entanto, somente esse levantamento não foi suficiente para discutir os processos erosivos. Assim, o autor reforça que deve-se considerar outras análises para discutir a erosão marginal, como: horizonte e toposequência do solo.

Nos pontos monitorados registraram baixas porcentagens de material coeso entre $(1,51 \%$ a $5,35 \%)$. O material apresentou taxas consideradas, especialmente a composição de silte entre 29,16 a $92,47 \%$. A composição do material das margens influencia no recuo da erosão, quanto mais quantidade de material arenoso, menor será a coesão no barranco, consequentemente alto índice erosivo (CASADO et al., 2002).

Os resultados mostram que a magnitude da erosão (cm/mês) foi mais intensa em $2018(0,164$ $\mathrm{cm} / \mathrm{mês}$ ); em 2017 foi registrada uma magnitude média de $0,141 \mathrm{~cm} / \mathrm{mês}$. Considerando a magnitude da erosão acumulada nos 24 meses a máxima foi de $11,37 \mathrm{~cm}$ e deposição de $\quad-0,98 \mathrm{~cm}$. Um dos fatores que minimiza o processo erosivo é a presença da mata ciliar (Floresta Ombrófila/Floresta Estacional/Savana/Floresta associada ao Planalto dos Parecis) bem conservada, onde as raízes estão dificultando o processo erosivo, promovendo resistência e estabilidade na margem (Tabela 3).

Tabela 3 - Taxa erosiva entre os anos de 2016, 2017 a 2018 no trecho do rio Teles Pires nos municípios Colider, Itaúba e Nova Canaã do Norte.

\begin{tabular}{c|c|c|c|c}
\hline \multirow{3}{*}{ Ponto } & \multirow{2}{*}{ Margem } & \multicolumn{2}{|c|}{ Magnitude da Erosão (cm/mês) } & $\begin{array}{c}\text { Magnitude da Erosão } \\
\text { Acumulado (cm) }\end{array}$ \\
\cline { 3 - 5 } & & $\mathbf{2 0 1 7}$ & $\mathbf{2 0 1 8}$ & $\mathbf{2 4}$ meses \\
\hline \multirow{2}{*}{5} & Esquerda & 0,008 & 0,132 & 3,168 \\
\hline \multirow{2}{*}{6} & Esquerda & 0,212 & 0,250 & 6,000 \\
\cline { 2 - 5 } & Direita & $-0,012$ & --- & --- \\
\cline { 2 - 5 } & Esquerda & $-0,022$ & 0,005 & $-0,120$ \\
\hline \multirow{2}{*}{7} & Direita & 0,313 & $-0,041$ & 2,884 \\
\cline { 2 - 5 } & Esquerda & 0,133 & 0,120 & 11,376 \\
\hline \multirow{2}{*}{8} & Direita & 0,592 & 0,474 & 3,120 \\
\cline { 2 - 5 } & Esquerda & 0,100 & 0,130 & 4,752 \\
\hline
\end{tabular}

Com a mudança no sistema fluvial para construção da UHE Colider, as margens do rio Teles Pires no P2, P3 e P4 foram desmatadas e soterradas, aumentando o nível da água. A maior profundidade média registrada foi no P4 com 22,02 m, sendo esse, o ponto mais próximo da usina. No P3, na área do reservatório, o talvegue é entalhado em formato de "U". As formas do fundo do leito são criadas pela interação da descarga e dos sedimentos transportados (CUNHA, 2015). O fluxo da água associado com transporte de sedimentos grossos em contato com o fundo rochoso pelo impacto hidráulico em movimentos turbilhonar condiciona o aparecimento de marmitas (PENTEADO, 1974). Nesse caso, o canal carreou sedimentos grossos com composição arenosa contribuindo com a formação de marmitas, observadas em 2016. No primeiro ano de monitoramento essa área registrou turbulência com presença de corredeiras (ANDRADE, 2019).

A taxa de erosão depende da velocidade do fluxo e material de origem (HOOKE, 1979; PAPANICOLAOU et al., 2006; KHORSANDI et al., 2015). Na margem direita do P5 a velocidade foi considerável, em 2017 ocorreu a deposição dos sedimentos e solo na margem convexa. O processo da força normal sobressaiu em relação a força cisalhante. A presença das raízes dificultou a desagregação do solo. Essa margem tem sido utilizada para atividades de pesca, sendo 47,67\% antropizada. Sendo assim, a movimentação de pessoas, influenciou para a retirada dos pinos, não encontrados no ano de 2018 (Tabela 3).

No P8, a margem direita sedimentou - 0,052 cm/mês em 2017 e erodiu 0,198 cm/mês em 2018 . Como citado anteriormente o aumento pluviométrico no ano de 2018 correlacionados a heterogeneidade da margem granular Franco arenosa contribuem com a predisposição a erosão. $\mathrm{Na}$ margem esquerda a erosão ocorreu $0,100 \mathrm{~cm}$ a $0,130 \mathrm{~cm}$ em 2017 e 2018, respectivamente. A velocidade foi análoga nos dois períodos monitorados $(0,63 \mathrm{~m} / \mathrm{s})$. Com a composição da margem

$\begin{array}{lllll}\text { Caminhos de Geografia } \quad \text { Uberlândia-MG } & \text { v. 21, n. 75 } & \text { Jun/2020 } & \text { p. 154-171 Página } 162\end{array}$ 
interestratificada não coesa e o aparecimento das raízes diminuem o processo cisalhante na face do barranco. Sendo assim, esses fatores dificultam ainda mais os estudos desses tipos de margens (KARMAKER e DUTTA, 2010).

O processo natural contribuiu com o volume de solo desintegrado de 0,413 a $32,763 \mathrm{~m}^{3}$, bem como a deposição de 2,520 $\mathrm{m}^{3}$, essa margem não foi remobilizada ou desintegrada (Tabela 4).

Tabela 4 - Taxa de solo erodido entre os anos de 2016, 2017 a 2018 no trecho do rio Teles Pires nos municípios Colider, Itaúba e Nova Canaã do Norte.

\begin{tabular}{|c|c|c|c|c|}
\hline \multirow[t]{2}{*}{ Ponto } & \multirow[t]{2}{*}{ Margem } & 2017 & 2018 & \multirow{2}{*}{$\begin{array}{c}\text { Em } 24 \text { meses } \\
\left(\mathrm{m}^{3}\right)\end{array}$} \\
\hline & & \multicolumn{2}{|c|}{ Volume do Solo Erodido $\mathrm{m}^{3}$} & \\
\hline 1 & Esquerda & 0,033 & 0,549 & 13,179 \\
\hline \multirow[t]{2}{*}{5} & Esquerda & 0,695 & 0,820 & 19,680 \\
\hline & Direita & $-0,103$ & 0 & 0 \\
\hline \multirow[t]{2}{*}{6} & Esquerda & $-0,0757$ & 0,017 & 0,413 \\
\hline & Direita & 0,801 & $-0,105$ & $-2,520$ \\
\hline \multirow[t]{2}{*}{7} & Esquerda & 0,362 & 0,326 & 7,834 \\
\hline & Direita & 1,705 & 1,365 & 32,763 \\
\hline \multirow[t]{2}{*}{8} & Esquerda & 0,336 & 0,437 & 10,483 \\
\hline & Direita & $-0,354$ & 1,346 & 32,314 \\
\hline
\end{tabular}

A erosão fluvial não ocorre de maneira contínua. A intensidade das chuvas, a velocidade do fluxo, a altura do barranco, o tipo de margem, em especial íngreme, a composição granulométrica interfere diretamente, aumentando o recuo das margens. Nesse processo a velocidade da água em contanto com o leito e as margens exercem a tensão do cisalhamento.

Avalia-se que a velocidade do fluxo combinado com a energia cinética liberada pelo impacto hidráulico das partículas arenosas (> concentração) transportadas em contato com a rocha contribui com a erosão por corrasão. Os grãos carreados ocasionaram impacto hidráulico formando fraturas no leito rochoso próximo a margem esquerda do $\mathrm{P} 1 \mathrm{ME}$, contribuindo assim com a formação de marmitas no fundo. A presença das rochas contribui com a velocidade do fluxo e o intenso processo de erosão por corrasão com a formação de marmitas, diminuindo o impacto cisalhante na face do barranco. Assim, os movimentos e a erosão estão ocorrendo mais verticalmente do que lateralmente. Destaca-se que a margem direita não foi monitorada, pois não é definida, caracterizada como área de deposição. As marmitas se formam pela formação de vórtices verticais que escavam buracos circulares e profundos na rocha do leito. (CHRISTOFOLETTI, 1980; STEVAUX e LATRUBESSE, 2017).

Avaliando o processo erosivo nos dois anos (2016-2018) monitorados no corredor fluvial, com extensão aproximada de $124 \mathrm{~km}$ no médio curso do rio Teles Pires, pode-se averiguar a erosão marginal, mesmo que em grau moderado, ocorrendo nos trechos a montante da área não alagada e, divisa entre as Usinas Hidroelétricas de Sinop e Colider, e a jusante da UHE Colider. A erosão promove mudanças de ordem natural, em que o impacto da corrente ou das partículas no barranco causa o desprendimento das partículas que são transportadas pelo fluxo ou são depositados ao sopé das margens. As mudanças no uso da terra nas adjacências contribuem com a erosão marginal, especialmente no trecho em estudo com a construção da UHE Colider e as atividades agropecuárias.

De acordo com Thorne (1978), Torres et al. (2012) a presença da vegetação dificulta a erosão e permite a deposição de sedimentos finos. Nos pontos em que não ocorreram a erosão e sim a deposição, sedimentos e solos depositados sobre os pinos, nos P5 e P8 (margem direita) e P6 (margem esquerda) em 2017 e P6 (margem direita) em 2018 podem estar associados aos sedimentos transportados pelo canal, bem como o solo carreados pelo escoamento superficial das vertentes durante o período chuvoso. Com a diminuição das precipitações atmosféricas os sedimentos se estabilizaram nas margens.

Em relação aos demais barrancos monitorados, averiguou-se que no $\mathrm{P7} M D$ teve um alto índice erosivo, e no cruzamento dos dados, a margem é composta com maior porcentagem de silte, $61,81 \%$ (Figura 4). Nesse ponto, está ocorrendo cisalhamento por solapamento, a erosão inicia-se na parte

Caminhos de Geografia Uberlândia-MG $\quad$ v. 21, n. $75 \quad$ Jun/2020 $\quad$ p. 154-171 Página 163


inferior, a corrente das ondas exerce pressão e com o tempo a parte superior tende a erodir no plano vertical, com o peso do material da margem e a composição não coesa contribui para a erosão. Assim, um dos fatores principais desse tipo de erosão é a flutuação do nível da água, permanecendo no período de cheia a parte inferior, e por estar mais em contato com o cisalhamento, intensifica a tensão, desintegrando as partículas, as quais podem permanecer próximo a margem ou serem transportados devido a velocidade do fluxo (CHRISTOFOLETTI, 1980).

Figura 4 - Representação da erosão marginal no P7 nos anos de 2016, 2017 e 2018.

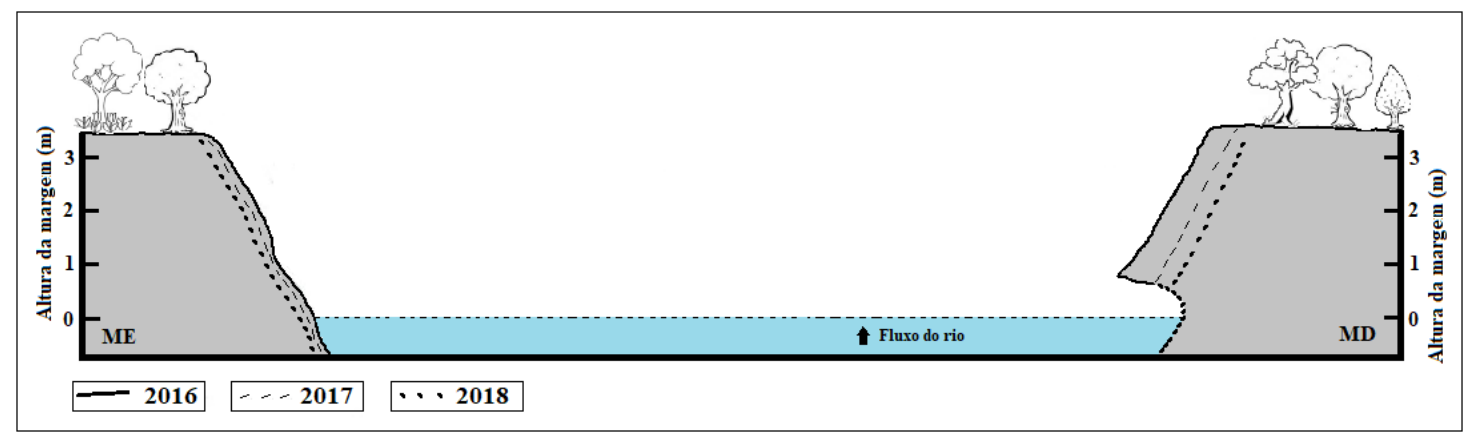

Em que: $M E=$ Margem esquerda; $M D=$ Margem direita .

A composição e a concavidade da margem, o grau de inclinação, a atividade antrópica na área (agropecuário) e a construção da usina, facilitaram para o processo erosivo no P7 MD. Estudos realizados no rio Madeira por Labadessa (2014) indicam que os processos naturais são os responsáveis pela erosão fluvial e são acentuados devido ao uso antrópico.

De acordo com Hooke (1979) e Cunha (2013) o comprimento dos pinos deve estar de acordo com as taxas erosivas. Assim, ao longo dos 24 meses monitorados a erosão marginal do trecho estudado no médio curso do rio Teles Pires variou desde sedimentação - 0,984 a 11,376 cm a magnitude da erosão acumulada (Tabela 4). Em alguns pontos em julho 2017, os pinos foram recolocados, cerca de $10 \%$, seguindo as orientações dos autores, caso ocorra imprevistos, os pinos podem ser recompostos ou substituídos, nesse caso não foram encontrados em 2018, totalizando 32\%. Deste modo, afirmado pelos valores, a técnica foi satisfatória para monitorar a erosão marginal. Hooke (1979) e Gatto (1988) ainda asseguram que essa técnica de pinos é apropriada para margens com maior quantidade de materiais finos (arenosos ou siltosos), sendo essas a composição mais quantificada nos barrancos estudados.

Petts (1979), Ma et al. (2012), Mendes (2018) afirmam que as alterações morfológicas após o represamento do rio podem não ocorrer em curto espaço de tempo, após o fechamento da barragem. E com a construção, o enchimento do lago e o funcionamento da usina hidrelétrica de Colider, a erosão aumentou $12 \%$, o que influenciou em mudanças significativas no médio curso do rio Teles Pires, especialmente a montante, onde a degradação foi em macro escala (retirada da vegetação, supressão das ilhas fluviais, alterações na hidrodinâmica, morfologia, desaparecimento das margens e implicações na carga sedimentar). E a jusante mesmo que em pequena escala, aumentou em alguns pontos, o processo erosivo das margens e a diminuição do débito.

Seguindo a cronologia e percentual a tendência é aumentar nos próximos anos. Essas alterações nas margens comprometem todo o sistema hidrossedimentológico Rosgen (2001) afirma que as transformações estão além da ordem física, compromete ainda a função biológica dos rios, com o alto índice de mortandade de peixes conforme os noticiários da empresa local.

As margens dos rios são consideradas limites transicionais, ou ecótonos, entre ecossistemas aquáticos e terrestres, e frequentemente alteram-se sob condições hidrológicas da própria dinâmica do rio. Essa funcionalidade hídrica condiciona a manutenção das áreas e habitats. Os barrancos formam um ecótono entre os ecossistemas terrestres com diversas estruturas e funções de habitat. A

$\begin{array}{lllll}\text { Caminhos de Geografia } & \text { Uberlândia-MG } & \text { v. } 21, \text { n. } 75 & \text { Jun/2020 } & \text { p. 154-171 Página } 164\end{array}$


Leila Nalis Paiva da Silva Andrade Marcela Bianchessi da Cunha Santino Celia Alves de Souza Fabio Leandro da Silva

Erosão marginal: mudanças geomorfológicas no rio Teles Pires (MT) decorrente da implantação de um barramento Juberto Babilônia de Sousa Cristiano Campos de Miranda

construção de uma barragem leva a mudanças no leito e na resistência aluvial (BETTES, 2008; FLORSHEIM et al., 2008).

Foram correlacionadas as variáveis respostas que influenciam a magnitude da erosão e pode-se verificar que as variáveis não foram significativas, os valores foram superiores a 0.05 . A profundidade e inclinação foram mais expressivas negativamente e a vazão e área estão influenciando positivamente o processo, conforme figura 5.

Figura 5 - Correlação das variáveis respostas do processo erosivo nas margens do rio Teles Pires.

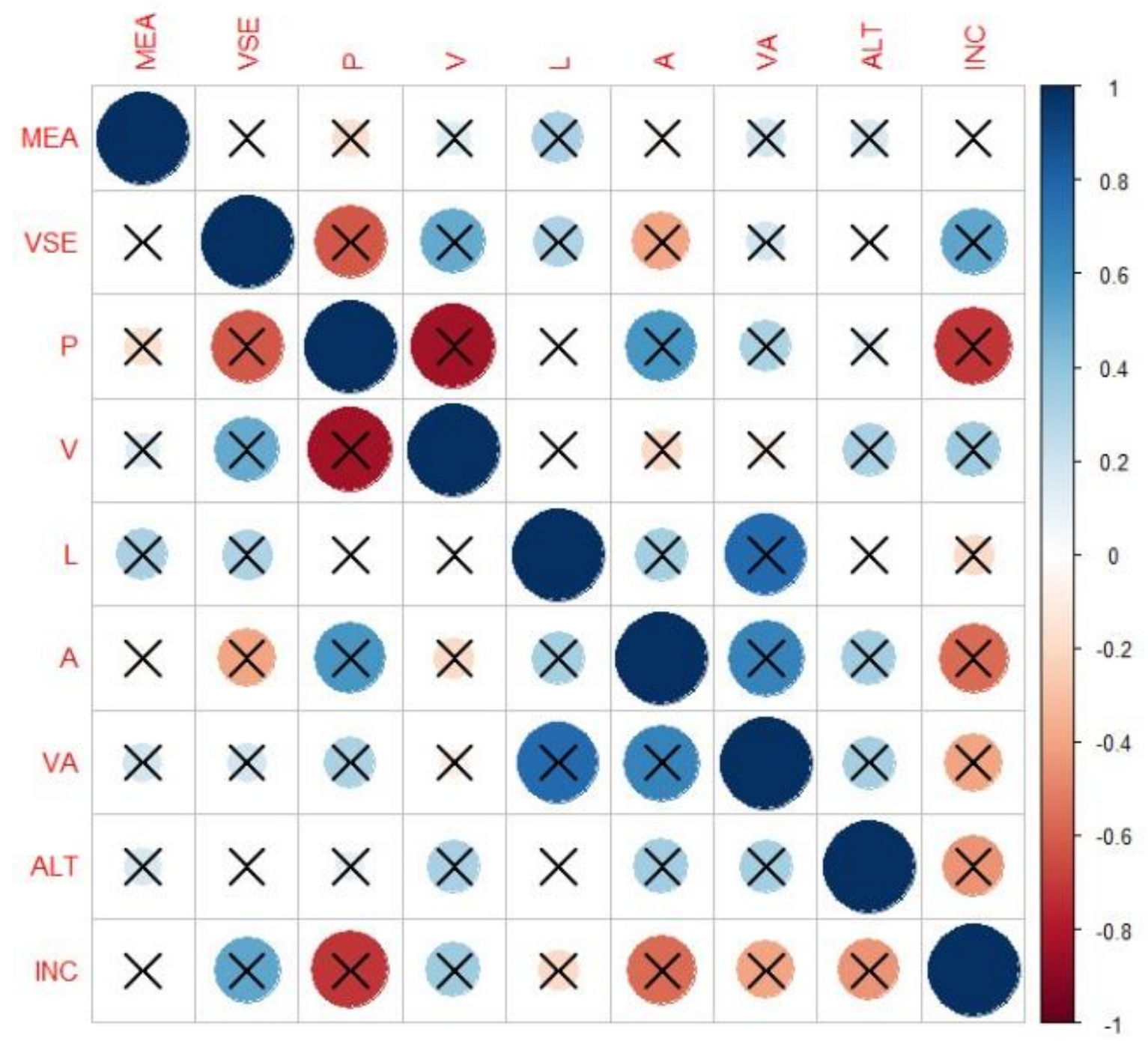

Em que: $M E A=$ Magnitude Erosão Acumulada, VSE=Volume de Solo Erodido; $P=$ Profundidade; $V=$ Velocidade; $L=$ Largura; $A=$ Área; Va= Vazão; ALT= Altura; INC= Inclinação.

O agrupamento quando trabalhado pela Análise do Componente Principal (PCA) pode-se averiguar que as variáveis em conjunto com o diagrama de ordenação gerado explicam $63 \%$ da variação dos dados nos dois eixos principais. Visto que o PC1 corresponde a $(0,3806=36,05 \%)$ e o PC2 $(0,2494=$ $24,94 \%)$. No primeiro eixo, a margem que mais erodiu P7MD foi influenciada negativamente pelas variáveis vazão, altura e largura e positivamente a velocidade com maior porcentagem de solo erodido. E os pontos P7ME e P8MD pela variante inclinação. No segundo eixo o P5MD a área influenciou com valores negativo enquanto a positivo no processo erosivo (Figura 6).

$\begin{array}{lllll}\text { Caminhos de Geografia } \quad \text { Uberlândia-MG } & \text { v. } 21, \text { n. } 75 & \text { Jun/2020 } & \text { p. 154-171 Página } 165\end{array}$


Figura 6 - Análise dos componentes principais no processo de erosão marginal.

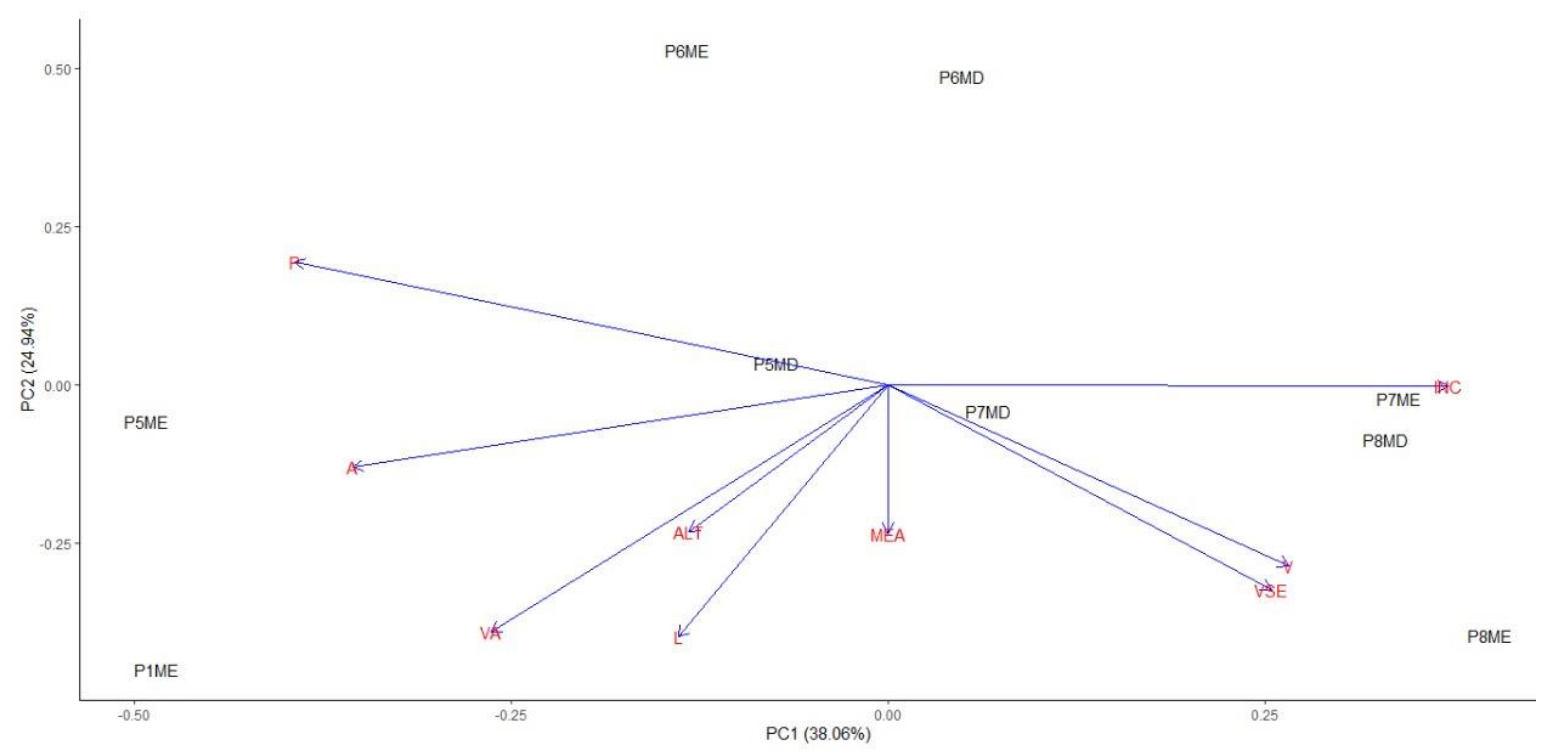

Em que: $M E A=$ Magnitude Erosão Acumulada, VSE= Volume de Solo Erodido; $P=$ Profundidade; $V=$ Velocidade; $L=$ Largura; $A=$ Área; Va= Vazão; ALT= Altura; INC= Inclinação.

Pondera-se, ainda, que os valores erosivos mensurados no rio Teles Pires são menores se comparados aos outros rios da bacia Amazônica: Madeira, Solimões e Tapajós. Sendo que esse processo é conhecido regionalmente como terras caídas (CARVALHO e CUNHA, 2011; FARIAS e CARNEIRO, 2012; PACHECO et a., 2012; LABADESSA, 2014).

\section{CONSIDERAÇÕES FINAIS}

Os pontos monitorados a montante e jusante da UHE Colider registrou mudanças na paisagem. No ano de 2016, a paisagem a montante da usina era de ambiente lótico com várias corredeiras e com profundidade média que variava de $1,44 \mathrm{~m}$ a 5,38 $\mathrm{m}$. Em 2018, as transformações devido a construção e enchimento do lago tornou um ambiente lêntico com profundidade de 19,74 a 22,08 m. Mudanças hidrogeomorfológicas ocorreram na calha, margens e várias ilhas submersas prejudicando o habitat de várias espécies.

Verificou-se que a erosão das margens pela técnica de pinos ocorreu lentamente. E em alguns pontos houve acúmulo de sedimentos nos pinos.

Com a Análise do Componente Principal (PCA) pode verificar que as variáveis quando agrupadas explicou $63 \%$ dos fatores correlacionados a erosão das margens. Contudo, todas as transformações que ocorreu para instalação e funcionamento da UHE Colider nesse ambiente fluvial implicará mudanças de ordem física e ambiental.

\section{Agradecimentos}

Agradecemos ao projeto "Bacia hidrográfica do rio Teles Pires: dinâmica fluvial e empreendimentos hidroelétricos entre os municípios de Nova Canaã do Norte e Itaúba, Mato Grosso", financiado pelo Edital Universal 005/2015, processo oㅡ 224752/2015 da Fundação de Amparo à Pesquisa do Estado de Mato Grosso - FAPEMAT, pelo apoio financeiro que possibilitou os trabalhos de campo e a sistematização dos dados tratados neste artigo e pelas bolsas de Iniciação Científica. Também à Universidade do Estado de Mato Grosso (UNEMAT) e Universidade Federal de São Carlos pelo apoio financeiro e logístico.

$\begin{array}{llllll}\text { Caminhos de Geografia } & \text { Uberlândia-MG } & \text { v. 21, n. } 75 & \text { Jun/2020 } & \text { p. 154-171 Página } 166\end{array}$




\section{REFERÊNCIAS}

ALLAN, J. D.; CASTILLO, M. M. Stream Ecology: Structure and function of running Waters. $2^{\mathrm{a}}$ Edição. Springer, 2007.

ALMEIDA, G. C. P. de. Caracterização Física e Classificação dos Solos. Universidade Federal de Juiz de Fora Faculdade de Engenharia Departamento de Transportes, 2004. Disponível em: http://ufrrj.br/institutos/it/deng/rosane/downloads/material\%20de\%20apoio/APOSTILA_SOLOS.pdf.

Acesso em: 17 de janeiro de 2019.

ANDRADE, L. N. P. da S. Efeitos da implantação da UHE Colider na dinâmica fluvial e na qualidade da água do curso médio do rio Teles Pires (Mato Grosso). 2019. 262 fls. Tese (Doutorado em Ciências) Programa de Pós Graduação em Ecologia e Recursos Naturais. Universidade Federal de São Carlos. São Carlos, 2019.

ARAUJO, A. P. de.; ROCHA, P. C. Avaliação espaço-temporal de erosão de margens no córrego do Cedro em Presidente Prudente, São Paulo, Brasil. In: Encontro dos Geógrafos da América Latina, 2012. Disponível

em:

2019http://observatoriogeograficoamericalatina.org.mx/egal12/Procesosambientales/Hidrologia/14.pdf . Acesso em: 24 de janeiro de 2019.

BALASUBRAMANIAN, A. Fluvial processes and landforms. Technical Report. August, 2010. Disponível https://www.researchgate.net/publication/309630899_FLUVIAL_PROCESSES_AND_LANDFORMS/d ownload. Acesso em: 31 de janeiro de 2019.

BANDEIRA, A. A. Evolução do processo erosivo na margem direita do rio São Francisco e eficiência dos enrocamentos no controle da erosão. 2005, 205 fls. Dissertação (Desenvolvimento e Meio Ambiente). Universidade Federal De Sergipe, 2005. Disponível em: http://livros01.livrosgratis.com.br/cp022153.pdf. Acesso em: 19 de janeiro de 2019.

BETTES, R. Sedimenttransport e alluvial resistance in rivers. Joint Defra. Environment Agency Flood and Coastal Erosion Risk Management ReD Programme, 2008. Disponível em: https://www.therrc.co.uk/MOT/References/EA_DEFRA_Sediment_transport_and_alluvial_resistance_i n_rivers.pdf. Acesso em: 15 de janeiro de 2019.

BORTOLUZZI, E. C.; PETRY, C. Partículas minerais: da rocha ao sedimento. In: POLETO, C. (org.). Ambiente e Sedimentos. Porto Alegre: ABRH, 2008, cap. 1, p. 1-37.

BRASIL. Ministério de Minas e Energia. Secretaria Geral. Projeto RADAMBRASIL: Levantamento de recursos naturais: Folha SC.21 - Juruena, geologia, geomorfologia, pedologia, vegetação e uso potencial da terra. Rio de Janeiro, v. 20.1980.

CARVALHO, J. A. L.; CUNHA, S. B. da C. Terras caídas e consequências sociais na costa do Miracauera, município de Itacoatiara- Amazonas, Brasil. Revista Geográfica de América Central. Número Especial EGAL, 2011- Costa Rica. II Semestre 2011 p. 1-16. Disponível em: https://core.ac.uk/download/pdf/48869573.pdf. Acesso em: 01 de agosto de 2019.

CARVALHO, N. de O.; HORA, M. de. A. G. M. Hidrossedimentometria. In: POLETO, C. (org.). Sedimentologia fluvial: estudos e técnicas. $2^{a}$ edição. Porto Alegre: ABRH, 2018, cap. 1, p. 9-60.

CASADO, A. P. B.; HOLANDA, F. S. R.; ARAÚJO FILHO, F. A. G.; YAGUIU, P. Evolução do processo erosivo na margem direita do rio São Francisco (Perímetro Irrigado Cotinguiba/Pindoba - SE). Revista Brasileira de Ciência do Solo. V. 26, 2002, p. 231-239. Disponível em: http://www.scielo.br/pdf/rbcs/v26n1/24.pdf. Acesso em: 14 de janeiro de 2019. https://doi.org/10.1590/S0100-06832002000100024

CHRISTOFOLETTI, A. Geomorfologia. São Paulo: Editora Blücher, 1980.

Geomorfologia fluvial: o canal fluvial. São Paulo: Edgard Blücher, 1981.

COELHO, A. L. N. Geomorfologia fluvial de rios impactados por barragens. Caminhos de Geografia. Uberlândia v. $9, \quad$ n. 26 Jun/2008, p. $16-32$. Disponível em:

$\begin{array}{lllll}\text { Caminhos de Geografia } \quad \text { Uberlândia-MG } & \text { v. 21, n. } 75 \quad \text { Jun/2020 } & \text { p. 154-171 Página } 167\end{array}$


http://www.seer.ufu.br/index.php/caminhosdegeografia/article/view/15721. Acesso em: 15 de outubro de 2018.

CORREA, G. T.; SOUZA FILHO, E. E. de. Avaliação dos processos de erosão marginal no arquipélago floresta japonesa (alto rio Paraná). Geografia. Londrina v. 18, n. 2, 2009. Disponível em: http://www.uel.br/revistas/uel/index.php/geografia/. Acesso em: 14 de janeiro de 2019.

CUNHA, S. B.; GUERRA, A. J. T. Degradação ambiental. In: GUERRA, A. J. T.; CUNHA, S. B. (orgs.). Geomorfologia e Meio Ambiente. Rio de Janeiro: Bertrand, 1996.

CUNHA, S. B. da. Geomorfologia Fluvial. In: GUERRA, A. J. T.; CUNHA, S. B. da. Geomorfologia: uma atualização de bases e conceitos. $12^{a}$ ed. Rio de Janeiro: Bertrand Brasil, 2013, cap. 5, p. 211 252.

Canais fluviais e a questão ambiental. In: CUNHA, S. B. da.; GUERRA, A. J. T. (orgs.). A questão ambiental: diferentes abordagens. 9a ed. Rio de Janeiro: Bertrand Brasil, 2015, cap.7, p. 219-239.

DIAS, W. A. Dinâmica erosiva em margens plenas de canal fluvial. 2012, 102 fls. Dissertação (Mestrado em Geografia). Universidade Estadual de Ponta Grossa. Ponto Grossa, 2012.

EMBRAPA. Empresa Brasileira de Pesquisa Agropecuária. Sistema brasileiro de classificação de solos. 3aㅡ ed. rev. ampl. Brasília, DF, EMBRAPA, 1997.

FARIAS, E. M. B.; CARNEIRO, D. de S. Alterações geomorfológicas no rio Amazonas Santarém/PA. Revista Geonorte. Edição Especial, V.2, N.4, 2012, p. 72-79. Disponível em: www.periodicos.ufam.edu.br/revista-geonorte/article/view/2059/1938. Acesso em: 01 de agosto de 2019).

FERNANDEZ, O. V. Q. Erosão Marginal no Lago da UHE Itaipu (PR). Tese de Doutorado. Instituto de Geociências e Ciências Exatas, Rio Claro. 1995.

- Mudanças no Canal Fluvial do Rio Paraná e Processos de Erosão nas Margens: Região de Porto Rico, PR. Dissertação de Mestrado, UNESP, Instituto de Geociências e Ciências Naturais. Rio Claro. 1990.

FERNANDEZ, O. V. Q.; FULFARO, V. J. Magnitudes e processos da erosão marginal no rio Paraná, trecho de Porto Rico, PR. Geografia. Rio Claro, 18 (1): 97-114, abril 1993. Disponível em:https://www.researchgate.net/profile/Oscar_Quinonez_Fernandez/publication/301650061_Fernan dez_Fulfaro_1993/links/571fc55008aed056fa2357c6/Fernandez-Fulfaro 1993. Pdf?origin=publication_deital. Acesso em: 29 de janeiro de 2019.

FLORSHEIM, J. L.; MOUNT, J. F.; CHIN, A. Bank erosion as a desirable attribute of rivers. BioScience. Vol. 58 No. 6, June 2008. Disponível em: https://academic.oup.com/bioscience/article/58/6/519/235969. Acesso em: 01 de fevereiro de 2019. https://doi.org/10.1641/B580608

GATTO, L. W. Techniques for measuring reservoir bank erosion. US Army Corps of Engineers. Cold Regions Research e Engineering Laboratory, 1988. Disponível em: https://apps.dtic.mil/dtic/tr/fulltext/u2/a191400.pdf. Acesso em: 06 de março de 2019.

HOOKE, J. M. An analysis of the Processes of river bank erosion. Journal of Hydrology. 42(1):3962, June $1979 . \quad$ Disponível em: https://www.researchgate.net/publication/245098417_An_Analysis_of_the_Processes_of_River_Bank _Erosion. Acesso em: 05 de março de 2019. https://doi.org/10.1016/0022-1694(79)90005-2

HUGUES, D. J. Rates of Erosion on Meandrer Arcs. In: GREGORY, K. J. River Channel Changes. Chihester: Jonh Wiley, 1977. p. 193-205.

KARMAKER, T.; DUTTA, S. Modeling composite river bank erosion in an alluvial river bend. In: DITTRICH, A.; KOLL, K. ABERLE; GEISENHAINER. (ed.). River Flow. Bundesanstalt für Wasserbau, 2010, 1315 - 1322 p. Disponível em: https://izw.baw.de/e-medien/river-flow2010/PDF/B5/B5_06.pdf. Acesso em: 01 de fevereiro de 2019. 
Leila Nalis Paiva da Silva Andrade Marcela Bianchessi da Cunha Santino Celia Alves de Souza Fabio Leandro da Silva Erosão marginal: mudanças geomorfológicas no rio Teles Pires (MT) decorrente da implantação de um barramento Cristiano Campos de Miranda

KHEIRALLA, K. M.; SIDDEG, A. S. Control over river bank erosion: a case study of Ganetti Station, Northern States, Sudan. Journal of Earth Science e Climatic Change. Volume 6, 2015, p. 1-5. Disponível em: https://doi.10.4172/2157-7617.1000287. Acesso em: 01 de fevereiro de 2019.

KHORSANDI, H.; FAGHIRI, G. A.; ASADZADEH, A. The rate of bank erosion of meandering rivers. Conference: 2nd, International conference on scour and erosion, At Nanyang Technological University, Singapore, Volume: 2; 131-137, 2015. Disponível em: https://www.researchgate.net/publication/273886332_The_Rate_Of_Bank_Erosion_Of_Meandering_ Rivers/download. Acesso em: 04 de março de 2019.

LABADESSA, A. S. "Terras caídas", as causas e implicações socioeconômicas: uma análise preliminar na comunidade de Calama - baixo rio Madeira/RO. Boletim Paranaense de Geociências. 71-1 (2014) 12-20. Disponível em: https://revistas.ufpr.br/geociencias/article/view/24930. Acesso em: 19 de novembro de 2018. https://doi.org/10.5380/geo.v71i0.24930

LAWLER, D. M.; COUPERTHWAITE, J.; BULL, L. J.; HARRIS, N. M. Bank erosion events and processes in the Upper Severn basin. Hidrology and Earth System Sciences. 1 (3), 1997, p. 523534. Disponível em: $<\mathrm{https}: / / w w w . r e s e a r c h g a t e . n e t / p u b l i c a t i o n / 243214053$ Bank_erosion_events_and_processes_in_the Upper_Severn_Basin/download>. Acesso em: 04 de janeiro de 2019. https://doi.org/10.5194/hess-1$\underline{523-1997}$

MA, Y.; HUANG, H. Q.; NANSON, G. C.; LI, Y.; YAO, W. Channel adjustments in response to the operation of large dams: the upper reach of the lower Yellow River. Geomorphology. 2012. Disponível em: http://ro.uow.edu.au/scipapers/4279. Acesso em: 31 de janeiro de 2019.

MELLO, N. A. de. Relação entre a fração mineral do solo e qualidade de sedimentos: o solo como fonte de sedimentos. In: POLETO, C.; MERTEN, G. H. (orgs.). Qualidade dos sedimentos. $2^{\underline{a}}$ edição (revisado e ampliado). Porto Alegre: ABRH, 2013, cap. 2, p. 47-76.

MENDES, A. B. Análise sinérgica da vida útil de empreendimentos hidrelétricos em cascata: o caso do rio Araguaia. In: POLETO, C. (org.). Sedimentologia fluvial: estudos e técnicas. $2^{\underline{a}}$ edição. Porto Alegre: ABRH, 2018, cap. 4 p. 115-152.

MEYBECK, M.; FRIEDRICH, G.; THOMAS R.; CHAPMAN, D. Rivers. In: CHAPMAN, D. (ed.). Water quality qssessments: a guide to use of biota, sediments and water in environmental monitoring. Second Edition, 1996, cap. 6, p. 246-324.

MINELLA, J. P. G.; MERTEN, G. H. Aplicação das características químicas e físicas dos sedimentos na modelagem dos processos de emissão de sedimentos em bacias hidrográficas. In: In: POLETO, C.; MERTEN, G.H. (orgs.). Qualidade dos sedimentos. 2ª edição (revisado e ampliado). Porto Alegre: ABRH, 2013, cap.9, p. 259-285.

MIRANDA, R. B.; ESTIGONI, M. V.; MAUD, F. F. A influência do assoreamento nos reservatórios de centrais hidrelétricas. In: POLETO, C. (org.). Sedimentologia fluvial: estudos e técnicas. $2^{\mathrm{a}}$ edição. Porto Alegre: ABRH, 2018, cap.5, p. 157-190.

PACHECO, J. B.; BRANDÃO, J. C. M.; CARVALHO, J. A. L. de. Geomorfologia fluvial do rio Solimões/Amazonas: estratégias do povo vazeano do sudoeste do careiro da várzea. Revista Geonorte. Edição Especial, V.2, N.4, p.542 - 554, 2012. Disponível em: www.periodicos.ufam.edu.br/revista-geonorte/article/view/2106/1983. Acesso em: 01 de agosto de 2019.

PAPANICOLAOU, A. N.; DEY, S.; RINALDI, M.; MAZUMDAR, A. Research issues for riverine bank stability analysis in the $21^{\text {st }}$ century. IIHR-Hydroscience e Engineering. The University of lowa City, 2006. Disponível em: https://www.iihr.uiowa.edu/wp-content/uploads/2013/06/TR-457-ResearchIssues.pdf. Acesso em: 01 de março de 2019.

PENTEADO, M. M. Fundamentos de geomorfologia. Fundação Instituto Brasileiro de Geografia e Estatística. Rio de Janeiro, 1974.

PETTS, G. E. Complex response of river channel morphology subsequent to reservoir construction. Progress in Physical Geography. 3(3), September, 1979, P. 329-362. Disponível em: https://www.researchgate.net/publication/249822672_Complex_Response_of_River_Channel_Morph

$\begin{array}{lllll}\text { Caminhos de Geografia } \quad \text { Uberlândia-MG } & \text { v. 21, n. } 75 \quad \text { Jun/2020 } & \text { p. 154-171 Página } 169\end{array}$ 
Leila Nalis Paiva da Silva Andrade Marcela Bianchessi da Cunha Santino Celia Alves de Souza Fabio Leandro da Silva Erosão marginal: mudanças geomorfológicas no rio Teles Pires (MT) decorrente da implantação de um barramento Juberto Babilônia de Sousa Cristiano Campos de Miranda

ology_to_Reservoir_Construction. Acesso em: 31 de janeiro de 2019. https://doi.org/10.1177/030913337900300302

PINTO, A. A. S. Estabilização de margens fluviais. Uma abordagem multifuncional. 2017, fls. 410. Dissertação (Mestrado em Engenharia). Universidade do Porto. Porto, 2017.

POIZOT, E.; MÉAR, Y.; BISCARA, L. Sediment Trend Analysis through the variation of granulometric parameters: A review of theories and applications. Earth-Science Reviews. N. 86, 2008, p. 15-41. https://doi.org/10.1016/i.earscirev.2007.07.004

POMEROL, C.; LAGABRIELLE, I.; RENARD, M.; GUILLOT, S. Princípios de Geologia: técnicas, modelos e teorias. 14 $\stackrel{\text { a }}{\mathrm{e}}$ ed. Porto Alegre: Bookman, 2013.

RAMOS, Y. S.; NASCIMENTO, N. V. do.; FARIAS, M. S. S. de.; FERNANDES, A. H. M.; NETO, J. Q. Degradação física das áreas de entorno do reservatório da usina hidrelétrica Luiz Gonzaga/PE BRASIL. Revista Verde. Mossoró, RN, v. 7, n. 5, dezembro de 2012 p. 132-139. (Edição Especial). Disponível em: http://revista.gvaa.com.br. Acesso em: 15 de janeiro de 2019.

RESENDE, M.; CARVALHO FILHO, A.; LANI, J. L. Características do solo e da paisagem que influenciam a susceptibilidade à erosão. In: SIMPÓSIO SOBRE MANEJO E CONSERVAÇÃO DO SOLO NO CERRADO, Campinas, 1992. Anais... Campinas: Fundação Cargill, 1992. P. 32-67.

RICCOMINI, C.; ALMEIDA, R. P. de.; GIANNINI, P. C. F.; MANCINI, F. Processos fluviais e lacustres e seus registros. In: TEIXEIRA, W.; FAIRCHILD, T. R.; TOLEDO, M. C. M. de.; TAIOLI, F. (org.). Decifrando a Terra. $2^{a}$ ed. São Paulo: Nacional. 2009, p. 306-333.

RINALDI, M.; DARBY, S. E. Modelling river-bank-erosion processes and mass failure mechanisms: progress towards fully coupled simulations. Vol.11, 2007, p. 213-239. Disponível em: http://doi:10.1016/s0928-2025(07)11126-3. Acesso em: 04 de janeiro de 2019. https://doi.org/10.1016/S0928-2025(07)11126-3

ROSGEN, D. L. A. Practical method of computing streambank erosion rate. Wildland Hydrology, Inc. Pagosa Springs, Colorado, 2001. Disponível em: https://semspub.epa.gov/work/01/554370.pdf. Acesso em: 10 de janeiro de 2019.

RUBIO, M. F. Gênese e dinâmica de erosões em margens de reservatórios. Pesquisa e desenvolvimento no estudo de caso nas UHEs Chavante e Rosana (rio Paranapanema, SP/PR). 2014. 283 f. Tese (Doutorado em Geografia Física). Faculdade de Filosofia, Letras e Ciências Humanas. Universidade de São Paulo. São Paulo, 2014.

SILVA, A. M.; SCHULZ, H. E.; CAMARGO, P. B. Erosão e hidrossedimentologia em bacias hidrográficas. $2^{a}$ ed. São Carlos: RiMa, 2007.

SILVA, L. N. P. da. Bacia hidrográfica do Córrego das Pitas-MT: dinâmica fluvial e o processo de Ocupação, como proposta de gestão dos recursos hídricos. 2009. 146 f. Dissertação (Mestrado em Ciências Ambientais) - Universidade do Estado de Mato Grosso, Cáceres, 2009. Disponível em: <http://www.unemat.br/prppg/ppgca/teses/2009/17.pdf>. Acesso em: 20 jan. 2017

SILVA, A.; SOUZA FILHO, E. E.; NEVES, S. M. A. S. Erosão marginal e sedimentação no rio Paraguai no município de Cáceres (MT). Revista Brasileira de Geociências. 41(1): 76-84, março de 2011. Disponível em: http://www.scielo.br/pdf/bjgeo/v41n1/2317-4692-bjgeo-41-01-76.pdf. Acesso: 15 de janeiro de 2019. https://doi.org/10.25249/0375-7536.20114117684

SOUZA, C. A. Dinâmica do corredor fluvial do Rio Paraguai entre a cidade de Cáceres e a Estação Ecológica da Ilha de Taiamã-MT. 2004. Tese (Doutorado em Geografia). Universidade Federal do Rio de Janeiro. Rio de Janeiro, 2004.

SOUZA, C. A.; CUNHA, S. B. Pantanal de Cáceres-MT: Dinâmica das Margens do Rio Paraguai entre a cidade de Cáceres e a estação ecológica da ilha de Taiamã-MT. Revista Eletrônica da Associação dos Geógrafos Brasileiros, Seção Três Lagoas - MS, v. 1, 2009. p. 18 - 42.

SOUZA, J. O. P. de.; ALMEIDA, J. D'arc M. de. Processos fluviais em terras secas: uma revisão. OKARA: Geografia em debate, v.9, n.1, p. 108-122, 2015. Disponível em: https://www.researchgate.net/publication/283017170. Acesso em: 15 de outubro de 2018. 
STEVAUX, J.C.; LATRUBESSE, E. M. Geomorfologia fluvial. São Paulo: Oficina de textos, 2017, p. 59-81.

SUGUIO, K. Geologia Sedimentar. São Paulo: Edgard Blücher, 2003.

THORNE, C.R. Processes of bank erosion in river channels. School of Environmental Sciences, March 1978.

Disponível

em: https://www.researchgate.net/publication/33922206_Processes_of_Bank_Erosion_in_River_Channels /download. Acesso em: 19 de janeiro de 2019.

TORRES, F. T. P.; MARQUES NETO, R.; MENEZES, S.O. Introdução à geomorfologia. São Paulo: Cengage Learning, 2012.

WOOD, P. J.; ARMITAGE, P. D. Biological Effects of Fine Sediment in the Lotic Environment. Environmental Management. Vol. 21, No. 2, p. 203-217. 1997. Disponível em: https://www.researchgate.net/publication/14200730_Biological_Effects_of_Fine_Sediment_in_the_Loti c Environment/download. Acesso em: 01 de fevereiro de 2019 . https://doi.org/10.1007/s002679900019

Recebido em: 14/10/2019

Aceito para publicação em: 24/04/2020 